\title{
Correction to: Microfluidic resonators with two parallel channels for independent sample loading and effective density tuning
}

\author{
Jungchul Lee ${ }^{1,2^{*}} \mathbb{C}$, Faheem Khan ${ }^{3}$, Thomas Thundat ${ }^{4}$ and Bong Jae Lee ${ }^{1,2}$ (])
}

\section{Correction to: Micro and Nano Syst Lett (2020) 8:16 https://doi.org/10.1186/s40486-020-00119-8 \\ After the publication of our article [1], we realized that it did not include the important reference [2] that reported our earlier work on device fabrication and experimental setup. We apologize to readers for this omission.}

\section{Author details}

${ }^{1}$ Department of Mechanical Engineering, Korea Advanced Institute of Science and Technology, 291 Daehak-ro, Yuseong-gu, Daejeon 34141, Republic of Korea. ${ }^{2}$ Center for Extreme Thermal Physics and Manufacturing, Korea Advanced Institute of Science and Technology, Daejeon 34141, Republic of Korea. ${ }^{3}$ Fourien, Edmonton T6B2N2, Canada. ${ }^{4}$ Department of Chemical and Biological Engineering, University at Buffalo, New York 14260-4200, USA.
References

1. Lee J, Khan F, Thundat T, Lee B (2020) Microfluidic resonators with two parallel channels for independent sample loading and effective density tuning. Micro and Nano Syst Lett 8:16. https://doi.org/10.1186/s4048 6-020-00119-8

2. Lee J, Khan F, Thundat T, Lee J (2019) Dual channel microfluidic resonators for simultaneous measurements of liquid analytes. In: 20th International conference on solid-state sensors, actuators, and microsystems \& eurosensors XXXIII (Transducers \& Eurosensors XXXIII)

\section{Publisher's Note}

Springer Nature remains neutral with regard to jurisdictional claims in published maps and institutional affiliations.

Published online: 20 November 2020

The original article can be found online at https://doi.org/10.1186/s4048 6-020-00119-8.

\footnotetext{
*Correspondence: jungchullee@kaist.ac.kr

1 Department of Mechanical Engineering, Korea Advanced Institute of Science and Technology, 291 Daehak-ro, Yuseong-gu, Daejeon 34141, Republic of Korea

Full list of author information is available at the end of the article
}

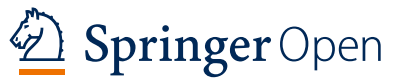

o The Author(s) 2020. This article is licensed under a Creative Commons Attribution 4.0 International License, which permits use, sharing, adaptation, distribution and reproduction in any medium or format, as long as you give appropriate credit to the original author(s) and the source, provide a link to the Creative Commons licence, and indicate if changes were made. The images or other third party material in this article are included in the article's Creative Commons licence, unless indicated otherwise in a credit line to the material. If material is not included in the article's Creative Commons licence and your intended use is not permitted by statutory regulation or exceeds the permitted use, you will need to obtain permission directly from the copyright holder. To view a copy of this licence, visit http://creativecommons.org/licenses/by/4.0/. 